\title{
Educational Approach of Blended Learning in Teaching Benign Paroxysmal Positional Vertigo in an Emergency Department
}

\author{
Khalid Bashir and Stephan Thomas \\ Emergency Department, Hamad General Hospital, Doha, Qatar
}

\begin{abstract}
Objective: To investigate the efficacy of blended learning $(B L)$ in emergency medical resident education related to the diagnosis and treatment of benign paroxysmal positional vertigo.

Study Design: A mixed-method study.

Place and Duration of Study: Emergency Department of Hamad General Hospital, Doha, Qatar from 1st to 31st January 2018. Methodology: Participating emergency medical residents were assigned to either traditional lecturing (TL) or BL groups and they used several instruments to review medical knowledge and skills before and after instruction. The residents' opinions were sought through semi-structured interviews.

Results: Students in both groups possessed similar knowledge and skills improvement, but reported a strong preference for TL.

Conclusion: There is a need for further evaluation of learning technology and students' learning styles to maximise medical education.
\end{abstract}

Key Words: Benign paroxysmal positional vertigo, Blended learning, Traditional lecturing, Education emergency medicine.

How to cite this article: Bashir K, Thomas S. Educational approach of blended learning in teaching benign paroxysmal positional vertigo in an emergency department. J Coll Physicians Surg Pak 2020; 30(3):299-303.

\section{INTRODUCTION}

Busy emergency department physicians are usually under substantial pressure to educate trainees along with providing emergency care. Recently, alternative educational approaches for trainees, such as online and web-based education, have been emphasised to allow physicians more time for educational and clinical roles. Current technological advances have made it easier for educators to augment lectures with online material. Despite their limitations, lectures in higher education continue to be a common approach for sharing large information in a short time. 1 One of the common criticisms of TL approach is the difficulty in maintaining students' attention for more than $10-15$ minutes. ${ }^{1}$ One condition that emergency medical residents (EMRs) study is benign paroxysmal positional vertigo (BPPV), a common medical problem in which patients suffer from a spinning sensation associated with certain head movements. It is diagnosed by a bedside head rotation test: and effective treatment is offered through bedside physical manoeuvres. ${ }^{2}$ Several patients fail to receive this potentially curative treatment due to the paucity of knowledge and confidence among treating physicians. . $^{3-5}$ To the best of authors' knowledge, there are no previous

Correspondence to: Dr. Khalid Bashir, Emergency Department, Hamad General Hospital, Doha, Qatar

E-mail:khalidbashir1@btinternet.com

Received: June 24, 2019; Revised: September 28, 2019;

Accepted: October 07, 2019 studies exploring the most appropriate educational approach in teaching about the diagnosis and treatment of BPPV.

Education methods are rapidly changing, and several studies have evaluated the most effective uses of technology in medical education. In one study, TL was compared with more interactive small group teaching methods among dental students' learning and skills acquisition. ${ }^{6}$ The knowledge gain was similar in both groups; however, small group teaching resulted in better skills acquisition. 6 In another study, TL was replaced by a flipped classroom approach and included discussions of cases, clinical procedures and a simulation. The residents favoured this flipped classroom approach due to deeper understanding and superior learning. ${ }^{7}$ In a different study, a group of pediatric rotating students were assigned to a TL group, while another group was allocated to an interactive discussion group. Although there was no difference in the knowledge attained in the two groups, the students preferred the interactive discussion group as compared to the lecture group. ${ }^{8}$

Modern technology can help educators engage students in the learning process more effectively. In one study, iPads and Skype were used for second-year medical students in a problem-based learning curriculum. The students felt that the use of this technology provided additional benefit in terms of live searching, making notes and better quality images. 9 One use of modern technology is $\mathrm{BL}$, an approach in which classroom and technology-based training methods are adopted and 
integrated. BL can be defined as an approach where classroom and technology-based training methods are adopted and integrated. ${ }^{10}$ It combines the best practices of online and TL by merging both the models to create a positive learning environment. Previous studies have shown mixed results for the use of $B L$ in medical education. 10 One meta-analysis showed that $\mathrm{BL}$ was more effective than TL and online learning. ${ }^{11}$ Another systematic review and meta-analysis concluded that $\mathrm{BL}$ was superior or at least equivalent to TL in knowledge acquisition in health professional education. ${ }^{12}$ However, other studies have found that $\mathrm{BL}$ in medical education is challenging and creates an extra burden both for the educators and the learners. 13,14

BL has not been previously studied for teaching of BPPV in emergency departments. This study primarily aimed to assess whether a BL approach proved more effective than a TL approach in EMRs' education regarding the management of BPPV. The secondary aim was to assess the residents' views on each educational approach.

\section{METHODOLOGY}

The data analysed was collected during educational activities of the EMR training programme at Hamad General Hospital, Doha, Qatar from 1st to 31st January 2018. Institutional ethics approval was obtained from the MRC of Hamad Medical Corporation (RP-16307). The study evaluated student response to different methods for teaching BPPV diagnosis and treatment.

The study centre, emergency department, caters to over 400,000 cases annually and hosts a four-year EMR training programme that is accredited by the international branch of the USA-based Accreditation Council for Graduate Medical Education. There are 12 EMRs in each year of the training programme. All EMRs are scheduled for didactic training on the same weekday throughout the year. This study was conducted on the didactic training days in January 2018.

The participants of the study included 38 EMRs, who were at different levels of training. There were no exclusion criteria for EMR participation in the study. EMRs were assigned to either the $\mathrm{BL}$ group or the standard-TL (control) group through simple randomisation; and then assessed before and after implementation of education using three performances: Dix-Hallpike manoeuvre $(\mathrm{DH})$ as rated 0 (worst) through 5 (perfect), Canalith reposition manoeuvre $(\mathrm{CR})$ as rated 0 through 5 , both by raters blinded to study group; and a written examination comprising 20 multiple-choice questions (MCQs).

The historical approach to EMR education at the study site comprised small group discussions and 5 hours of didactic lectures per week. MCQ testing is a regular part of the EMR programme and the demonstration of the physical manoeuvres, such as those ( $\mathrm{DH}$ and $\mathrm{CR}$ ) on which this study focused, has long been part of the EMR training. Residents practised manoeuvres on eight healthy volunteers. For the control group, TL (e.g. lecture and demonstrations) was emphasised. This group received a traditional 45-minute-long Power-Point-based lecture from one emergency department physician and then residents practised the manoeuvres under direct supervision. The lecture also included two videos. The first video showed DH for the diagnosis of BPPV; whereas, the second video exhibited two CR manoeuvres for the treatment of BPPV. For the BL group, the residents watched the internet-based Power-Point lecture slides and videos on a large screen in the auditorium and practised the manoeuvres on healthy volunteers without the help of faculty.

Each study group had the same evaluation process, which included an individual performance of the two manoeuvres ( $\mathrm{DH}$ and $\mathrm{CR}$ ) with adjudication of performance level on a 5-point scale (0-5). The ratings were standardised and tested for inter-rater reliability. Those executing the ratings were all senior EMR faculty who were unaware of the education group to which EMRs had been randomised. The entire senior faculty went through a calibration exercise on the ratings.

The MCQ test that was used to evaluate the EMRs' knowledge was prepared by an experienced emergency physician with the help of an ENT consultant colleague. To reduce bias, the same $M C Q$ test was administered before and after the educational sessions. The result ranged from 0 to 20 as there were 20 items on the test. One point was awarded for each correct answer. The test items had been used previously in EMR education at the study site.

The information collected in the study was recorded into a dataset in the statistical package stata (version 15MP, StataCorp, College Station, Texas USA), which was used for all graphing and analytics for this report. Categorical data proportions were reported with binomial exact confidence intervals (Cls). Cls were reported at the $95 \%$ level, except for use of one-sided $(97.5 \%)$ Cls around a point estimate of $0 \%$. For non-categorical data, normality was assessed using the Shapiro-Wilk test of departure from the null hypothesis of normal distribution (i.e. a non-significant $p$-value fails to reject $\mathrm{HO}$ of normal distribution). Normality was assessed separately for six groups of scores: of pre- and posteducation scores for each of the three evaluations $(\mathrm{DH}$, $\mathrm{CR}$ and $\mathrm{MCQ}$ ). Statistical significance was set at $\mathrm{p}<.05$.

\section{RESULTS}

The residents in the two groups were similar. Characteristics of the 38 participants are shown in Table I. The pre- and post-intervention scores on $\mathrm{DH}$ for the $\mathrm{BL}$ and control groups are shown in Table II. MCQ scores were distributed normally for both pre- and post-education 
Table I: Comparison between two study groups: face-to-face and blended learning.

\begin{tabular}{l|c|c|c|c}
\hline Parameters & $\begin{array}{c}\text { Face-to-face } \\
\text { group } \\
(\mathrm{n}=19)\end{array}$ & $\begin{array}{c}\text { Blended learning } \\
\text { group } \\
(\mathrm{n}=19)\end{array}$ & Total & $\mathrm{p}$-value \\
\hline Age (mean years) & $28.4 \pm 1.7$ & $27.8 \pm 1.8$ & $28.1 \pm 1.7$ & $<0.445$ \\
\hline Gender & $12(63.1 \%)$ & $13(68.4 \%)$ & $25(65.7 \%)$ & \\
Male & $7(36.9 \%)$ & $6(31.6 \%)$ & $13(34.3 \%)$ & 1.0 \\
Female & $2.5 \pm 1.1$ & $2.7 \pm 1.1$ & $2.6 \pm 1.1$ & $<0.889$ \\
\hline $\begin{array}{l}\text { Years of residency } \\
\text { (mean years) }\end{array}$ & & & & \\
\hline
\end{tabular}

Table II: Pre- and post-education scores for blended learning vs. standard education approaches.

\begin{tabular}{l|c|c|c}
\hline Study group & Assessment & $\begin{array}{c}\text { Pre-intervention } \\
\text { score median } \\
\text { (DH, CR) } \\
\text { or mean (MCQ) } \\
\text { with 95\% Cl }\end{array}$ & $\begin{array}{c}\text { Post-intervention } \\
\text { score median } \\
\text { (DH, CR) or } \\
\text { mean (MCQ) } \\
\text { with 95\% Cl }\end{array}$ \\
\hline $\mathrm{TL}$ & $\mathrm{DH}$ & $2(1.7-3.0)$ & $5(4.0-5.0)$ \\
\hline $\mathrm{BL}$ & $\mathrm{DH}$ & $2(0.7-3.0)$ & $5(4.0-5.0)$ \\
\hline $\mathrm{TL}$ & $\mathrm{CR}$ & $2(1.0-2.3)$ & $5(4.7-5.0)$ \\
\hline $\mathrm{BL}$ & $\mathrm{CR}$ & $2(0.7-3.0)$ & $5(5.0-5.0)$ \\
\hline $\mathrm{BL}$ & $\mathrm{MCQ}$ & $15.2(14.4-16.1)$ & $18.0(17.4-18.6)$ \\
\hline $\mathrm{BL}$ & $\mathrm{MCQ}$ & $15.1(13.7-16.5)$ & $17.8(16.9-18.7)$ \\
\hline
\end{tabular}

$B L=$ Blended learning; $C R=$ Canalith repositioning; $D H=$ Dix-Hallpike; $M C Q=$ Multiple-choice questions; $T L=$ Standard education.

Table III: Pre- and post-education scores for blended learning vs. standard education approaches.

\begin{tabular}{l|c|c}
\hline Assessment method & $\begin{array}{c}\text { p, pre-intervention vs. } \\
\text { post-intervention score }\end{array}$ & $\begin{array}{c}\text { Median (DH, CR) or mean } \\
\text { (MCQ) improvement } \\
(95 \% \mathrm{Cl}) \text { pre- to } \\
\text { post-intervention score }\end{array}$ \\
\hline $\mathrm{DH}: \mathrm{TL}$ group & .0002 & $2.0(2.0-3.0)$ \\
\hline $\mathrm{DH}: \mathrm{BL}$ group & .0002 & $2.0(2.0-4.0)$ \\
\hline $\mathrm{CR}: \mathrm{TL}$ group & .0001 & $3.0(2.0-3.0)$ \\
\hline CR: BL group & .0001 & $3.0(2.0-4.0)$ \\
\hline MCQ: TL group & .0001 & $2.8(2.1-3.5)$ \\
\hline MCQ: BL group & .0001 & $2.7(1.6-3.8)$
\end{tabular}

$B L=$ Blended learning; $C R=$ Canalith repositioning; $D H=$ Dix-Hallpike; $M C Q=$ Multiple-choice questions; $T L=$ Standard education.

assessments of both $T L$ and $B L$ groups. For $\mathrm{DH}$ and $\mathrm{CR}$ assessments, some scores were non-normal for either pre- or post-intervention assessments. Thus, medians and non-parametric methods were used to analyse $\mathrm{DH}$ and $\mathrm{CR}$ results; whereas, MCQ results were analysed with means and parametric methods.

For $\mathrm{DH}, \mathrm{CR}$ and $\mathrm{MCQ}$ evaluation sets, in both the TL and the $\mathrm{BL}$ groups, the post-intervention scores were significantly higher than pre-intervention scores. Table III shows univariate $p$ values and estimated median (for $\mathrm{DH}$ and $\mathrm{CR}$ ) or mean (for MCQ) differences between preand post-intervention scores. The median pre-intervention score for the $\mathrm{DH}$ test in TL was 2 with a $95 \% \mathrm{Cl}$ of 1.7 to 3.0 , while the median post-intervention score for the $\mathrm{DH}$ test in this group was 5 with a $95 \% \mathrm{Cl}$ of 4.0 to 5.0. The median pre-intervention score for the $\mathrm{DH}$ test in $\mathrm{BL}$ learning was 2 with a $95 \% \mathrm{Cl}$ of 0.7 to 3.0 , while the median post-intervention score for the $\mathrm{DH}$ test in this group was 5 with a $95 \% \mathrm{Cl}$ of 4.0 to 5.0 .
The median pre-intervention score for the CR test in TL was 2 with a $95 \% \mathrm{Cl}$ of 1.0 to 2.3 , while the median postintervention score for the CR test in this group was 5 with a $95 \% \mathrm{Cl}$ of 4.7 to 5.0 . The median pre-intervention score for the CR test in $\mathrm{BL}$ was 2 with a $95 \% \mathrm{Cl}$ of 0.7 to 3.0, while the median post-intervention score for the $\mathrm{CR}$ test in $\mathrm{F} 2 \mathrm{~F}$ group was 5 with a $95 \% \mathrm{Cl}$ of 5.0 to 5.0 .

The mean pre-intervention score for MCQ test in TL was 15.2 with a $95 \% \mathrm{Cl}$ of 14.4 to 16.1 , while the mean postintervention MCQ test score in this group was 18 with a $95 \% \mathrm{Cl}$ of 17.4 to 18.6 . The mean pre-intervention score for MCQ test in BL was 15.1 with a $95 \% \mathrm{Cl}$ of 13.7 to 16.5 , while the mean post-intervention MCQ test score in this group was 17.8 with a $95 \% \mathrm{Cl}$ of 16.9 to 18.7 . The post-intervention median score improvement from preintervention score for $\mathrm{DH}$ test in TL group was 2.0 points with $95 \% \mathrm{Cl} 2.0$ to 3.0 ( $p=0.002)$. The post-intervention median score improvement from pre-intervention score for $\mathrm{DH}$ test in $\mathrm{BL}$ group was 2.0 points with $95 \% \mathrm{Cl} 2.0$ to $4.0(\mathrm{p}=0.002)$. The post-intervention median score improvement from pre-intervention score for the $\mathrm{CR}$ test in the TL group was 3.0 points with $95 \% \mathrm{Cl} 2.0$ to 3.0 $(p=0.001)$. The post-intervention median score improvement from pre-intervention score for the CR test in the $\mathrm{BL}$ group was 3.0 points with $95 \% \mathrm{Cl} 2.0$ to 4.0 ( $\mathrm{p}=0.001$ ). The mean post-intervention score improvement from pre-intervention score for MCQ test in TL group was 2.8 points with $95 \% \mathrm{Cl} 2.1$ to 3.5 ( $p=0.001)$. The mean postintervention score improvement from pre-intervention score for MCQ test in BL group was 2.7 points with $95 \%$ Cl 1.6 to $3.8(p=0.001)$.

The final analysis step was comparison as to whether the pre- to post-intervention score improvements were greater for the $\mathrm{BL}$ than TL groups. For both the $\mathrm{DH}$ and $\mathrm{CR}$ evaluations, the median difference between didactic lecturing score improvements and BL score improvements was $0(95 \% \mathrm{Cl},-1$ to 1$)$. For the MCQ evaluation, the mean improvement seen in TL was .1 higher than that of the mean improvement seen in $\mathrm{BL}$, but the $95 \% \mathrm{Cl}$ $(-1.2$ to 1.4$)$ crossed the null value. The questionnaire response rate was $100 \%(n=38)$. Out of 38 residents, 25 preferred TL teaching to BL (66\%), which was statistically significant.

\section{DISCUSSION}

The learning styles of millennials in an emergency medicine residency programme in the country appear to be different from millennials of other western countries. A plausible reason for this preference may be their undergraduate education. ${ }^{14}$ All residents in the study had graduated from medical schools in the Middle East and Asia that followed traditional face-to-face teaching for knowledge transfer and apprenticeship. ${ }^{14}$

This study determined whether the use of a BL approach, as compared to a control 'standard' TL educational 
approach, was associated with marked improvement in post-educational testing. The study results clearly and consistently demonstrated that there were significant improvements in multiple types of assessment from the pre- to the post-education time-frame, but that those improvements were virtually identical with $B L$ and $T L$ approaches. The secondary aim was to gauge residents' preferences for an educational approach. Most residents favoured the TL approach over the BL approach for learning about BPPV. This outcome may be surprising to some as all the residents in this study were millennials (born between 1982 and 2004), a group often labelled as technology savvy self-learners who enjoy social networking and may prefer to learn through $\mathrm{BL}$ approaches that take advantage of contemporary technology media over old-style learning methods such as lectures. ${ }^{15}$ One study among medical students rotating in psychiatry found the students preferred a TL approach as the teachers were enthusiastic, knowledgeable and provided a structured training. ${ }^{15}$ One RCT assessed the effectiveness of BL where an e-learning module was added to TL for the acquisition of clinical and ultrasound of knee examination in a physiotherapy degree course. The knowledge gain was similar in both groups, but the skills acquired were significantly better in the BL group. ${ }^{16} \mathrm{At}$ present, the literature is divided on the suitability of $B L$ in improving knowledge and skills in medical education. In this study, BL resulted in equivalent knowledge improvement and significant reduction of faculty time in teaching EMR about the diagnosis and treatment of BPPV. BL may provide an alternative educational approach in improving knowledge and skills of BPPV. Further multicentre studies are recommend to explore the appropriateness of a BL approach in EMR education.

The first study limitation is that there may have been insufficient study numbers, in terms of both the number of EMRs and the variety of evaluation subjects. The number of EMRs does not seem to be a significant problem for overall results. Given the null (for $\mathrm{DH}$ and $\mathrm{CR}$ ) or near-null (for MCQ) point estimates for BL versus face-to-face learning differences in score improvements and given the narrow Cls for those estimates, there seems to be a low chance that a larger study would yield statistically significant differences. However, it is possible that an EMR education programme incorporating BL would have different effects on an EMR learning group at a particular level of training (e.g. first-year EMRs). The current analysis lacked the power to assess this question of $B L$ differential impact at different levels of training.

The second study limitation is that it is possible that $\mathrm{BL}$ works better (or worse) than standard education in certain types of educational scenarios other than those tested in this study. The current study is strengthened by its assessment of both written examination and physical- manoeuvre test performance, but it is possible that BL has different advantages or disadvantages for other types of learning.

The third limitation was the use of a questionnaire for gauging opinion; rather the better approach would have been a focus group discussion to get a detailed evaluation about each educational approach. The final limitation was the single-centre study; thus the results may not be applicable to other centres. As such, further studies are needed to endorse these results.

\section{CONCLUSION}

$T L$ and $B L$ teaching resulted in an equivalent increase in the knowledge and skills of EMRs regarding BPPV diagnosis and treatment. The learning styles of millennials in an emergency medicine residency programme in the country seem different from those of other countries as they prefer a TL approach to learn about BPPV. Modern technology may not provide better learning outcomes for millennial generation; thus alternative methods for supporting these learners must be found.

\section{ETHICAL APPROVAL:}

The study was approved by MRC of Hamad Medical Corporation (RP-16307/16).

\section{PATIENTS' CONSENT:}

The study was classified as an exempt category under Supreme Council of Health, Qatar guidelines, category 1, research conducted in established or commonly established setting involving normal educational practices. No formal consent was obtained. All residents volunteered to participate.

\section{CONFLICT OF INTEREST:}

Authors declared no conflict of interest.

\section{AUTHORS' CONTRIBUTION:}

KB: Conceived the study, obtained ethical approval and wrote the manuscript.

ST: Did the detailed statistical analysis, wrote the report, and overall supervision.

\section{REFERENCES}

1. Stuart J, Rutherford R. Medical student concentration during lectures. Lancet 1978; 2:514-6.

2. Bhattacharyya N, Gubbels SP, Schwartz SR. Clinical practice guidelines: Benign paroxysmal positional vertigo (Update). Otolaryngol Head Neck Surg 2017; 156:S1-47.

3. Bashir K, Alessai GS, Salem WA, Irfan FB, Cameron PA. Physical maneuvers: Effective but underutilized treatment of benign paroxysmal positional vertigo in the ED. Am J Emerg Med 2014; 32:95-6.

4. Bashir K, Abid AR, Felaya A, Masood M, Ahmad HA, Cameron P. Continuing lack of the diagnosis of benign paroxysmal 
positional vertigo in a tertiary care emergency department. Emerg Med Australas 2015; 27:378-9.

5. Arshad M, Abbas S, Qureshi IA. Delay in diagnosis and treatment of benign paroxysmal positional vertigo in current practice. J Ayub Med Coll Abbottabad 2013; 25:93-5.

6. Arias A, Scott R, Peters OA, McClain E, Gluskin AH. Educational outcomes of small-group discussion versus traditional lecture format in dental students' learning and skills acquisition. J Dent Educ 2016; 80:459-65.

7. King AM, Mayer C, Barrie M, Greenberger S, Way DP. Replacing lectures with small groups: The impact of flipping the residency conference day. West J Emerg Med 2018; 19:11-7.

8. Mosher J, Gjerde CL, Wilhelm M, Srinivasan S, Hagen S. Interactive discussion versus lecture for learning and retention by medical students. Focus Health Prof Educ 2017; 18:16-26.

9. George P, Dumenco L, Dollase R, Taylor JS, Wald HS, Reis SP. Introducing technology into medical education: Two pilot studies. Eur J Dent Educ 2013; 19:217-21.

10. Bonk CJ, Olson TM, Wisher RA, Orvis KL. Learning from focus groups: An examination of blended learning. J Distance Educ 2002; 17:97-118.
11. Means B, Toyama Y, Murphy R, Bakia M, Jones K. Evaluation of evidence-based practices in online learning: $A$ meta-analysis and review of online learning studies. Washington, DC. US Department of Education, 2009I; 93.

12. Liu Q, Peng W, Zhang F, Hu R, Li Y, Yan W. The effectiveness of blended learning in health professions: Systematic review and meta-analysis. J Med Internet Res 2016; 18:e2.

13. Rizvi NF, Gulzar S, Nicholas W, Nkoroi B. Barriers in adopting blended learning in a private university of Pakistan and East Africa: Faculty members' perspective. Mhealth 2017; 3:18.

14. Salim H, Lee PY, Ghazali SS. Perceptions toward a pilot project on blended learning in Malaysian family medicine postgraduate training: A qualitative study. BMC Med Educ 2018; 18:206.

15. Waljee JF, Chopra V, Saint S. Mentoring millennials. JAMA 2018; 319:1547-8

16. Arroyo-Morales M, Cantarero-Villanueva I, Fernandez-Lao C, Guirao-Pineyro M, Castro-Martin E, Diaz-Rodriguez L. A blended learning approach to palpation and ultrasound imaging skills through supplementation of traditional classroom teaching with an e-learning package. Man Ther 2012; 17:474-8. 